\title{
Investigation on Tool Deflection During Tapping
}

\author{
Felix Geßner ${ }^{(凶)}$, Matthias Weigold, and Eberhard Abele \\ Institute of Production Management, Technology and Machine Tools (PTW), \\ Technische Universität Darmstadt, Otto-Berndt-Str. 2, 64287 Darmstadt, Germany \\ f.gessner@ptw.tu-darmstadt.de
}

\begin{abstract}
Tapping is a challenging process at the end of the value chain. Hence, tool failure is associated with rejected components or expensive rework. For modelling the tapping process we choose a mechanistic approach. In the present work, we focus on the tool model, which describes the deflection and inclination of the tool as a result of the radial forces during tapping. Since radial forces always occur during tapping due to the uneven load distribution on the individual teeth, the tool model represents an essential part of the entire closed-loop model. Especially in the entry phase of the tap, when the guidance within the already cut thread is not yet given, radial forces can lead to deflection of the tool. Therefore, the effects of geometric uncertainty in the thread geometry are experimentally investigated, using optical surface measurement to evaluate the position of the thread relative to the pre-drilled bore. Based on the findings, the tool deflection during tapping is mapped using a cylindrical cantilever beam model, which is calibrated using experimental data. The model is then validated and the implementation within an existing model framework is described.
\end{abstract}

Keywords: Tapping $\cdot$ Deflection $\cdot$ Model

\section{Introduction}

In industrial applications and in everyday live, threaded joints are widely used as detachable connecting elements. The most used process for machining internal threads is tapping [1]. During tapping the thread is cut successively into the wall of an existing bore by the tooth of the tapping tool. Since the process is located at the end of the value chain, tool failure is associated with rejected components or expensive rework [2]. The industry is therefore constantly striving to increase process stability, to reduce failures or the need for human intervention [3]. To achieve this, it is necessary to increase the understanding of the tapping process especially regarding the effect of uncertainty.

Like all machining processes, drilling-tapping process chains are generally affected by uncertainty, since not all properties and process characteristics can be fully determined. Forms of geometrical uncertainty, which occur in tapping process chains, are shown in Fig. 1. In the process chain uncertainty can arise from the preceding or the current process step itself, or from the interlinking of both steps. Deviations of the pre-drill geometry, like variations in diameter, straightness or cylindrical shape may occur in the 
preceding process. Runout and synchronization errors are allocated in the current process step. Uncertainty arising from the interlinking of both process steps are positioning errors, like axis offset and inclined pre-drill bores [4]. Positioning errors, can be caused by misplacement, inaccuracy of the machine tool or reclamping of the part between the process steps [5].

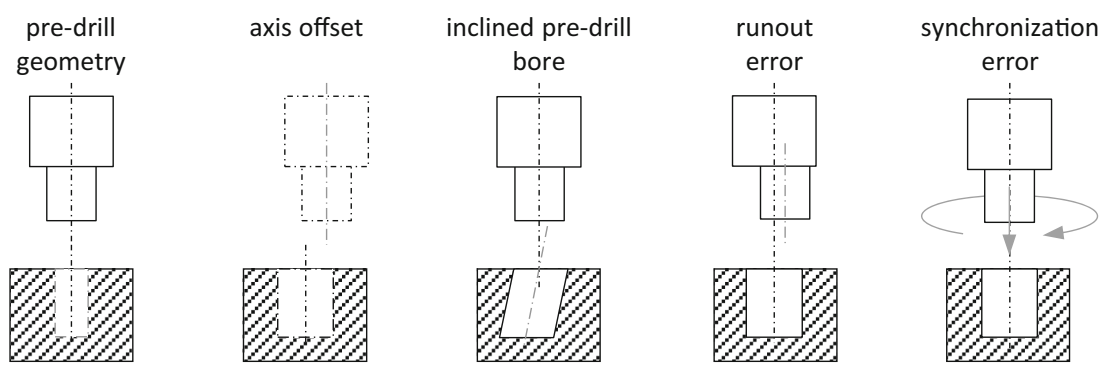

Fig. 1. Forms of uncertainty in a drilling-tapping process chain [4]

For the present work, the focus is mainly on axis offset and inclined pre-drill bores, that are relevant for tapping and other subsequent processes of drilling. Investigations on the tool deflection in reaming illustrate for example, that the axis offset leads to unbalanced radial forces during the entry phase of the reaming tool, which causes tool deflection and a center offset of the bore [6]. Just like the reaming tool, the tapping tool is not yet guided when entering the pre-drilled bore. In addition, when tapping, the cutting load is not homogeneously distributed over the cutting section and over the lands of the tap due to the individual tooth geometry [7] (see Fig. 2).

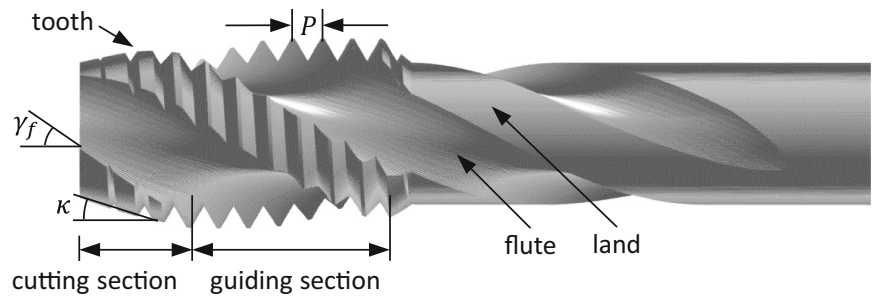

Fig. 2. General geometry of a blind-hole tapping tool

Although general descriptions of the tapping process can be found in numerous manuals, it has received less attention for research activities, than other processes like turning, milling or drilling [8]. This is also evident in studies on tool deflection since many studies exist for the milling process [9-12]. Kim et al. [9] describe the tool deflection during ball-end milling. They calculate the cutter deflection due to the cutting force using a two-step cylindrical cantilever beam and estimate the form error of the finished part. An extension of this approach is presented by Smaoui et al. [10] who compare the results of the analytical beam model to numeric and experimental model approaches. Zeroudi 
and Fontaine [11] use the analytical tool deflection model for tool path compensation. Another use of beam theory is presented by Moges et al. [12] to describe tool deflection in micro milling. A consideration of the effect of uncertainty on tool deflection are described by Hauer [6] for the reaming process, by Bölling [13] for valve guide and seat machining and by Hasenfratz [14] for milling of deep cavities in TiAl6V4. All three works use beam theory and Jeffcott rotor theory to reproduce the tool displacement as well as the dynamic effects of the fast-rotating tools.

The influences of process faults on tapping are described by Dogra et al. [2, 15]. They use a mechanistic model approach to predict the effect of axis offset, tool runout and synchronization errors on the resulting torque and forces. Mezentsev et al. [16, 17] describe the effect of axis offset and tool runout on tapping, with focus on the resulting radial forces and the thread geometry. The thread geometry is therein defined by the nominal diameter $D$, the core diameter $D_{1}$ and the pitch diameter $D_{2}$ (see Fig. 3). It should be noted, that neither Mezentsev et al. nor Dogra et al. take tool deflection into account.

Many studies already deal with the displacement of cutting tools due to resulting forces. The aim of this article is to extend the previous findings and to transfer them to tapping. For this purpose, the phenomenon of tool deflection during tapping is first described based on experimentally recorded data. This is followed by the derivation of a model that can be used to describe the phenomenon. Subsequently, the model created is calibrated and validated in experimental tests. Finally, the integration of the tool deflection model into an existing framework to simulatively investigate the effect of uncertainty on the tool deflection during tapping is described.

\section{Effect of Tapping Tool Deflection on Thread Geometry}

As described in [5], the diameters in the thread are not influenced by an offset between the pre-drilled bore and the thread. This includes the nominal diameter $D$, the core diameter $D_{1}$ and the flank diameter $D_{2}$ according to DIN 2244 [18]. Therefore, the detection of an axis offset is a challenging task. However, there is an influence on the profile height $\mathrm{H}_{4}$, which is influenced by the position of the centers of the described diameters in relation to each other [5]. Therefore, conclusions about the offset between the center axis of
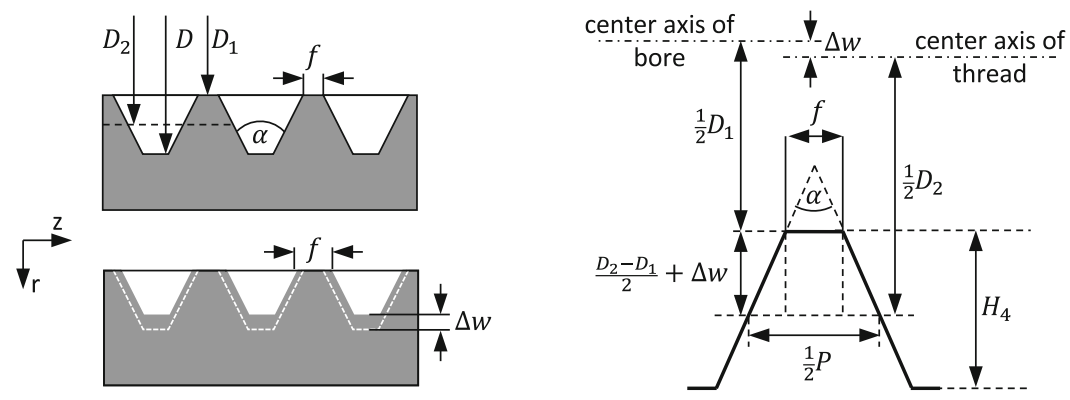

Fig. 3. Measuring the axis offset $\Delta w$ between the center axis of the pre-drilled bore and thread based on the width of flat $f$ 
the pre-drilled bore and the thread can be drawn based on the width of flat $f$, which is influenced by the profile height.

The offset $\Delta w$ between the thread and the pre-drilled bore at a specific position $z_{i}$ can be calculated using the following formula, where $P$ is the pitch of the thread, and $\alpha$ is the thread profile angle. In case of the M8 thread the values are $P=1.25 \mathrm{~mm}$ and $\alpha=60^{\circ}$.

$$
\Delta w\left(z_{i}\right)=\frac{\frac{P}{2}-f\left(z_{i}\right)}{2 \tan \left(\frac{\alpha}{2}\right)}-\frac{D_{2}-D_{1}}{2}
$$

To measure the width of flat $f$, the drilled threads are cut open perpendicular to the axis offset and the thread profile is recorded with the optical surface measuring device Alicona Infinite Focus G5. As the diameters can no longer be measured after cutting, the calculation of the axial offset of the thread relative to the pre-drilled bore is based on the width of flat $f_{\text {ref }}$ of a reference thread produced with the same tools.

$$
\Delta w\left(z_{i}\right)=\frac{f_{\mathrm{ref}}-f\left(z_{i}\right)}{2 \tan \left(\frac{\alpha}{2}\right)}
$$

If the position of the pilot bore $w_{\text {bore }}$ is known, the position of the thread $w_{\text {thread }}$ can be calculated based on the position of the thread relative to the pilot bore as follows:

$$
w_{\text {thread }}\left(z_{i}\right)=w_{\text {bore }}\left(z_{i}\right)+\Delta w\left(z_{i}\right)=w_{\text {bore }}\left(z_{i}\right)+\frac{f_{\text {ref }}-f\left(z_{i}\right)}{2 \tan \left(\frac{\alpha}{2}\right)}
$$

The deflection is evaluated for M8x1.25 threads (see Fig. 4). The threads were machined on a GROB G350 machining center, using a tool holder with minimum length compensation and internal cooling with an emulsion containing 7\% oil. The used M8 machine tap has a helix angle $\gamma_{f}$ of $45^{\circ}$ and chamfer form C. The tolerance class is ISO2/6H. The tap is made of HSS-E and has a GLT-1 coating. The cutting depth is $19.75 \mathrm{~mm}$, the cutting speed is $15 \mathrm{~m} / \mathrm{min}$ and the workpiece material is $42 \mathrm{CrMo} 4$. The pre-drilled bore is a blind hole with a nominal diameter of $6.8 \mathrm{~mm}$. During the pre-drilling, uncertainty was applied in the form of an offset of the pilot bore of $\pm 280 \mu \mathrm{m}$ and an inclination with an angle of $\pm 1^{\circ}$.

The deflection of the thread for a pre-drilled bore with axis offset shows that most of the deflection of the tool happens directly when entering the bore. The resulting inclination of the tapping tool then leads to an increasing deviation of the center axis of the thread over the drilling depth. The effect can be seen for both positive and negative axis offsets. With an inclined pre-drilled bore, there is only a slight deflection when first entering the pre-drilled bore, thus the tapping tool is guided in a central position. However, the tool deflection increases with increasing drilling depth. This can be attributed to unbalanced radial forces due to the greater material thickness on one side. With the combination of axial offset and inclined pilot hole, the inclination of the tapping tool, as it enters the pre-drilled bore, causes the tap to follow the bore center axis, which in turn leads to uniform chip removal. Thus, the combination of uncertainty may reduce the negative effects. 

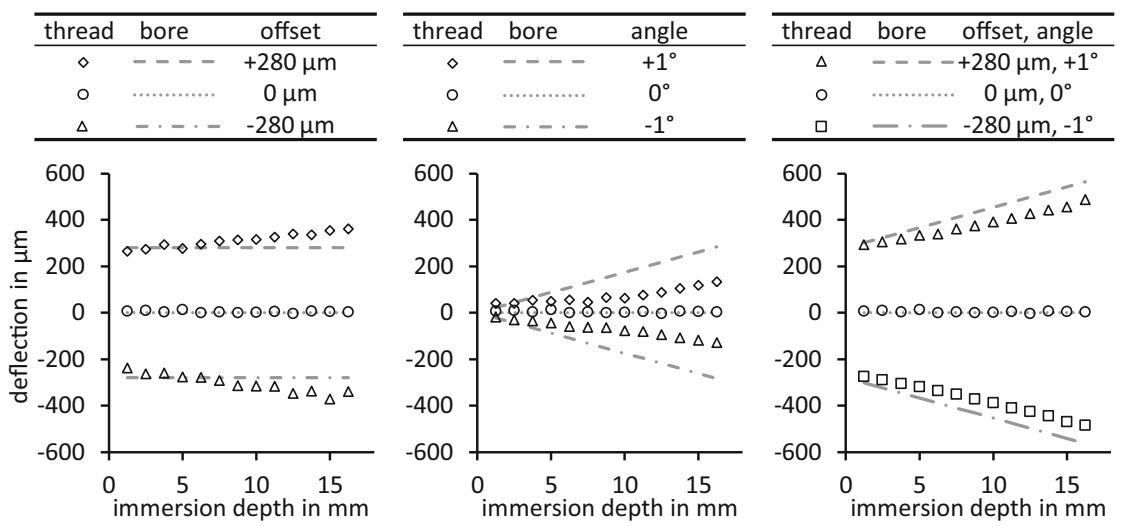

Fig. 4. Calculated thread deflection based on the experimentally measured width of flat

\section{Model for Determining Tool Deflection During Tapping}

\subsection{Model Description}

Based on the findings of Sect. 2, the system of tool holder and tapping tool is modelled using Euler-Bernoulli-Beam theory. First, a substitute model is set up to map the tool deflection due to lateral forces. Therefore, the tapping process is divided into two stages. In the first stage, until the time $t_{e}$, the tool is assumed to be unguided. Here, only a radial force $F_{R}$ acts on the tool, which corresponds to the resulting force due to the chip removal of the tap $F_{\text {res. }}$.

$$
F_{R}=F_{\text {res }}, \text { for } t<t_{e}
$$

Based on the resulting lateral force $F_{\text {res }}$, the deflection $w$ and the inclination $w^{\prime}$ of the tool can be calculated during this period. After the time $t_{e}$ the tool is assumed to be guided. The guidance of the tap in the already cut thread is mapped with a sliding sleeve, which in addition to the force $F_{R}$ also takes up the moment $M_{A O}$ (see Fig. 5).
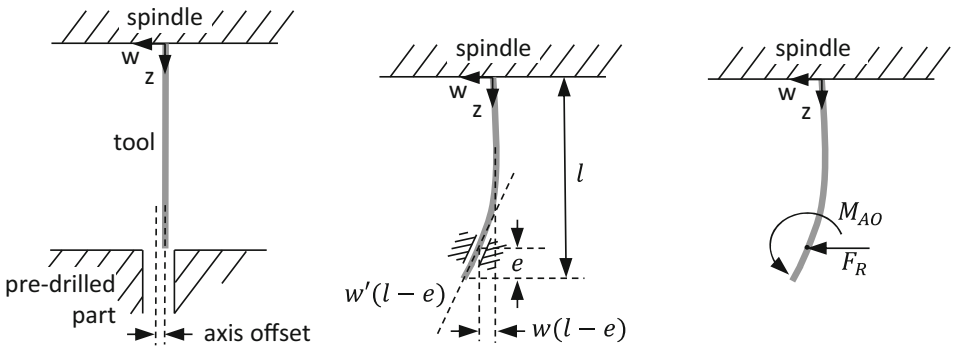

Fig. 5. Mechanical substitute model of the tapping tool before entering the pre-drilled bore (left), the guidance of the tool in the thread modelled with a sliding sleeve (middle) and the free body diagram of the deflected tool (right) 
Based on the findings from Sect. 2, the axial offset and the inclination of the sliding sleeve are assumed to be constant for the rest of the tapping process. Only the position relative to the spindle changes depending on the current cutting depth $e(t)$.

$$
\begin{gathered}
w(l-e(t))=\text { const., for } t \geq t_{e} \\
w^{\prime}(l-e(t))=\text { const., for } t \geq t_{e}
\end{gathered}
$$

To accurately map the tool holder and the tool, a cylindrical cantilever beam with three segments is used (see Fig. 6). Regarding boundary conditions it is assumed that the cantilever beam has a fixed end on the left side $(z=0)$ and a free end on the right side $(z=a+b+c)$. Furthermore, the inclination $w^{\prime}(z)$ is assumed to be a continuous function over all segments of the beam. The first segment represents the tool holder with a length $a$, a Young's modulus $E_{C}$ and an area moment of inertia $I_{1}$. The second two segments represent the tool. The tool used is a M8x1.25 tap, as described in Sect. 2, with a central cooling channel of diameter $0.5 \mathrm{~mm}$ and reinforced shank according to DIN 371 [19]. Therefore, the tool is represented by two beam segments with the length $b$ and $c$, which share the same Young's modulus $E_{T}$ but differ in their diameter and consequently in the area moment of inertia $I_{2}$ and $I_{3}$.
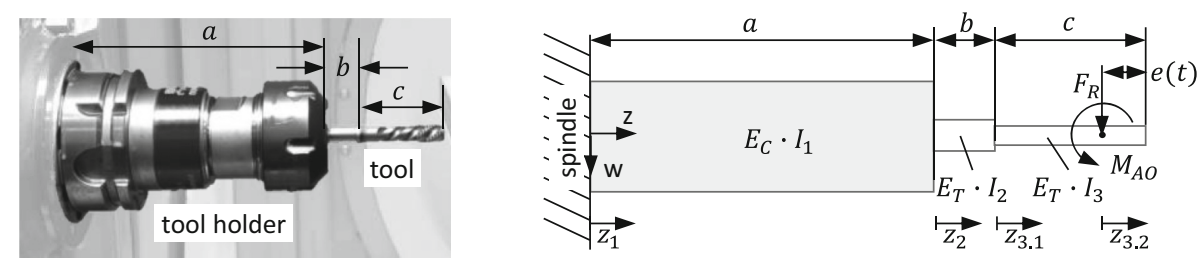

Fig. 6. Euler-Bernoulli-Beam model of the tool holder and tool system

The deflection of the beam shown in Fig. 6 can be determined from the respective curvature $w^{\prime \prime}$ of the individual segments due to the prevailing bending moment $M(z)$.

$$
w^{\prime \prime}(z)=-\frac{M(z)}{E I}
$$

Double integration of the equations thus established and determination of the integration constants using the boundary conditions described yields the following formulas for the deflection for the respective segments.

$$
\begin{gathered}
w_{1}\left(z_{1}\right)=\frac{1}{E_{C} I_{1}}\left[F_{R}\left(-\frac{1}{6} z_{1}^{3}+\frac{1}{2}(a+b+d) z_{1}^{2}\right)-\frac{1}{2} M_{A O} z_{1}^{2}\right] \\
w_{2}\left(z_{2}\right)=\frac{1}{E_{T} I_{2}}\left[F_{R}\left(-\frac{1}{6} z_{2}^{3}+\frac{1}{2}(b+d) z_{2}^{2}\right)-\frac{1}{2} M_{A O} z_{2}^{2}\right]+w_{1}^{\prime}(a) z_{2}+w_{1}(a) \\
w_{3.1}\left(z_{3.1}\right)=\frac{1}{E_{T} I_{3}}\left[F_{R}\left(-\frac{1}{6} z_{3.1}^{3}+\frac{1}{2} d z_{3.1}^{2}\right)-\frac{1}{2} M_{A O} z_{3.1}^{2}\right]+w_{2}^{\prime}(b) z_{3.1}+w_{2}(b) \\
w_{3.2}\left(z_{3.2}\right)=w_{3.1}^{\prime}(d) z_{3.2}+w_{3.1}(d)
\end{gathered}
$$




\subsection{Model Calibration}

To calibrate the beam model, the deflection is measured at several points on the tool and the tool holder while a lateral force is applied to the tool by means of a pneumatic piston. To apply the force in a targeted manner, a nut is screwed and glued onto the tool. In steps of $50 \mathrm{~N}$, a lateral force $F_{R}$ of $250 \mathrm{~N}$ is applied with a distance of $e=3.4 \mathrm{~mm}$ to the tip of the tool and the deflection is measured at six points on the tool and the tool holder. The test setup and the deflection resulting from a lateral force of $50 \mathrm{~N}$ are shown in Fig. 7.
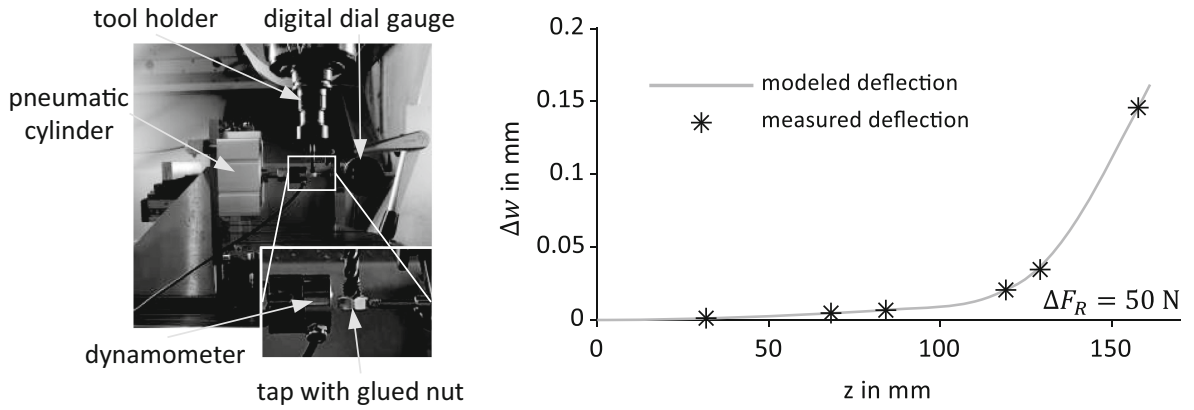

Fig. 7. Experimental setup for the calibration tests and deflection for a lateral force of $50 \mathrm{~N}$

For the calibration of the flexural rigidity for the three segments the averaged gradient of the deflection $\Delta w(z)$ at the measuring points resulting of an increasing load of $\Delta F_{R}=$ $50 \mathrm{~N}$ (in the range of 50 to $200 \mathrm{~N}$ ) is used. Transforming the Eqs. (8), (9) and (10) and inserting $\Delta F_{R}, \Delta w(z)$ as well as the measured lengths $a, b$ and $c$ yields the flexural rigidity of the segments listed in Table 1 .

Table 1. Results of the calibration

\begin{tabular}{l|l|l|l}
\hline Parameter & Value & Parameter & Value \\
\hline$a$ & $102.5 \mathrm{~mm}$ & $\mathrm{E}_{\mathrm{C}} \mathrm{I}_{1}$ & $3392.1 \mathrm{Nm}^{2}$ \\
\hline$b$ & $21.1 \mathrm{~mm}$ & $\mathrm{E}_{\mathrm{T}} \mathrm{I}_{2}$ & $40.49 \mathrm{Nm}^{2}$ \\
\hline$c$ & $37.6 \mathrm{~mm}$ & $\mathrm{E}_{\mathrm{T}} \mathrm{I}_{3}$ & $8.97 \mathrm{Nm}^{2}$ \\
\hline
\end{tabular}

\subsection{Experimental Model Validation}

The tool displacement model is validated using experimental tests performed on a DMC $75 \mathrm{~V}$ linear machining center. Tool holder, tapping tool, cutting speed and workpiece material are chosen the same as in Sect. 2. The radial forces are measured with a Kistler 9272 dynamometer. The tool displacement is measured using two eddy current sensors pointing perpendicular on the shaft of the tool with a position of $z=128.4 \mathrm{~mm}$. The sensors are attached to the spindle housing via a mounting system as shown in Fig. 8 . To protect the measuring equipment from chips a protection shield was applied, and the 
tests were carried out under dry conditions. The cutting depth of the tap is reduced to $16 \mathrm{~mm}$, to prevent the sensors from colliding with the component. Subtracting the length of the cutting section this results in a usable thread length of $12.25 \mathrm{~mm}$, which equals approximately $1.5 \mathrm{xD}$.
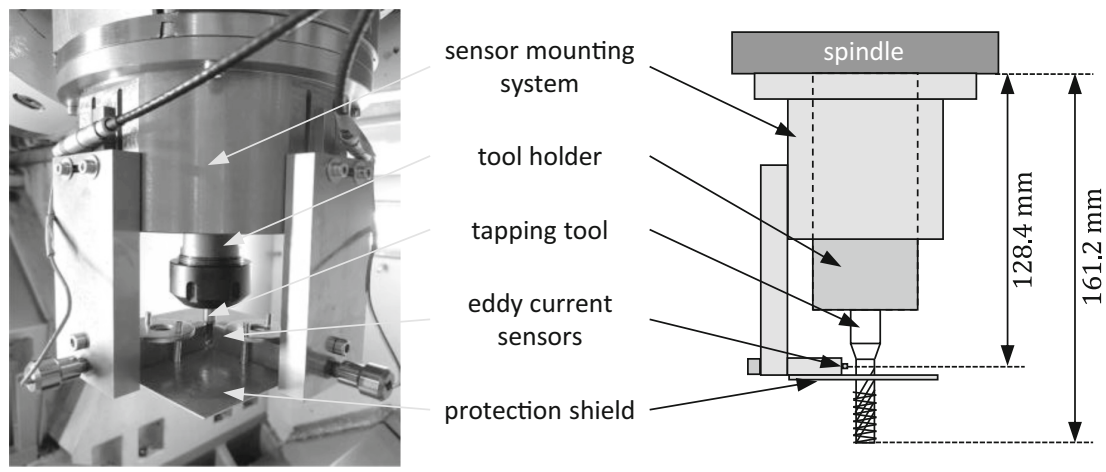

Fig. 8. Experimental setup to measure the tool deflection during tapping

The measured lateral force and tool deflection at the sensor position are shown in Fig. 9. In addition, the tool deflection at the sensor position is calculated using the calibrated model from Sect. 3.2, the measured lateral force and the current cutting depth $e(t)$. The measured and the calculated deflection show good accordance.

The start of the spindle rotation is set as time $t=0 \mathrm{~s}$. The deflection before this is constant and is set as the zero point. With the start of the spindle rotation, a periodic signal with the frequency of the spindle rotation is visible. This can be interpreted as the combined runout error of the tool and the tool holder. When the tool cuts into the predrilled bore, a reduction in the amplitude of the runout error can be seen. This indicates that the tool is guided in the already cut thread. For the tests with specifically applied axis offset, a step in the measured lateral force and the measured tool deflection can be observed when entering the pre-drilled bore at $t=0.67 \mathrm{~s}$.
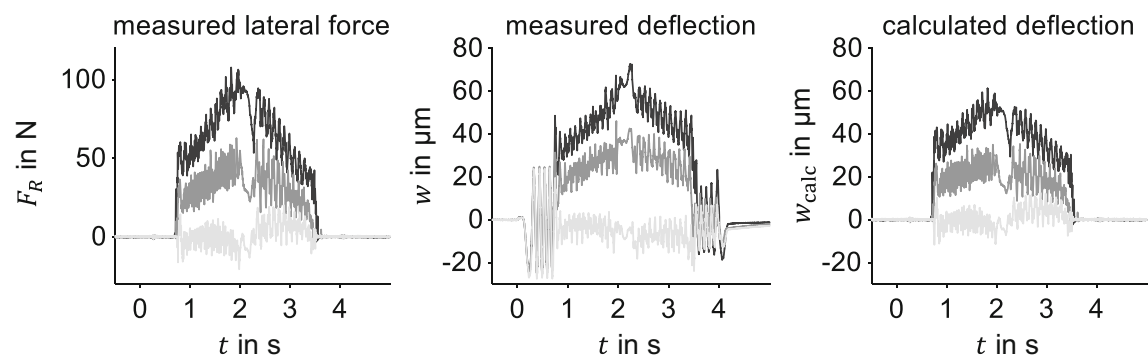

$$
200 \mu \mathrm{m} \quad 100 \mu \mathrm{m}
$$$$
0 \mu \mathrm{m}
$$

Fig. 9. Measured lateral force (left), measures deflection (middle) and calculated deflection based on the measured lateral forces (right) at the sensor position of $z=128.4 \mathrm{~mm}$ 
The subsequent increase in force and deflection is due to the increasing cutting depth $e$, which has the effect of shortening the distance between the sensor and the guided part of the tool, as described in Sect. 3.1. After approx. $2 \mathrm{~s}$, the rotation of the tool is stopped and reversed to unscrew the tool from the thread. During the unscrewing process, forces and deflection decrease analogously to the cutting process. However, since no more chips are removed here, it can be concluded that the lateral force is caused by the tool deflection due to the guidance in the already cut thread. It can therefore be summarized that the assumptions of the model are also shown in the experiment.

\section{Model Framework}

The calibrated and validated tool deflection model can be implemented within a mechanistic tapping model. Mechanistic modelling is a widely used method for torque and force prediction. The approach is based on the chip load-cutting force relationship according to Koenigsberger and Sabberwal [20]. The general structure of the mechanistic framework, as described by Kapoor et al. [21], combines this relationship with other submodels to a closed loop model. For the tapping process, as presented in this work, the closed loop model is shown in Fig. 10.

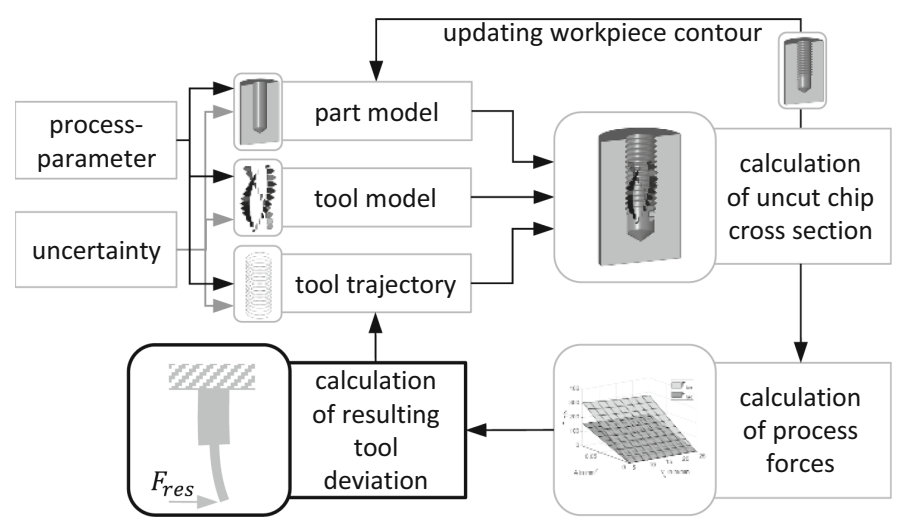

Fig. 10. Framework of the mechanistic process model

Therein the local time-dependent chip sizes considering uncertainty, as shown in Fig. 1, are calculated using a chip cross-section model [5]. The geometrically calculated chip sizes are then used as input for the empiric force model, presented in [7]. The tool deviation due to the resulting process forces is calculated using the tool deflection model, presented in Sect. 3. The influence of the tool deflection is fed back into the chip cross-section model via the manipulation of the tool trajectory.

\section{Summary and Outlook}

In this article it was shown how uncertainty in form of positioning errors can affect the tapping process and the thread geometry. With the measurement and evaluation of the 
width of flat, a method was described to determine the axial offset between the pre-drilled bore and the thread. Based on the knowledge gained from this, a substitute beam model was developed, which represents the tool deflection in the unguided and guided state of the tapping process. The model was calibrated and validated experimentally. Finally, the integration of the model into an existing framework was described, which can be used in further works to predict and describe the effect of uncertainty on the tapping process.

Acknowledgement. The authors would like to thank the German Research Foundation (DFG) for funding the research activities at the Collaborative Research Centre (CRC) 805 - Control of Uncertainty in Load-Carrying Structures in Mechanical Engineering.

\section{References}

1. Brandão, G.L., Silva, P.M.d.C., de Freitas, S.A., et al.: State of the art on internal thread manufacturing: a review. Int. J. Adv. Manufact. Technol. 110, 3445-3465 (2020). https://doi. org/10.1007/s00170-020-06107-x

2. Dogra, A.P.S., Kapoor, S.G., DeVor, R.E.: Mechanistic model for tapping process with emphasis on process faults and hole geometry. J. Manufact. Sci. Eng. 124, 18-25 (2002). https:// doi.org/10.1115/1.1430237

3. Patel, H.J., Patel, B.P., Patel, S.M.: A review on thread tapping operation and parametric study. Int. J. Eng. Res. Appl. (IJERA) 2, 109-113 (2012)

4. Pelz, P.F., et al.: Mastering uncertainty in mechanical engineering. Springer (2021)

5. Abele, E., Geßner, F.: Spanungsquerschnittmodell zum Gewindebohren: Modellierung der Auswirkung von Unsicherheit auf den Spanungsquerschnitt beim Gewindebohren. wt Werkstattstechnik online, vol. 108, pp. 2-6 (2018)

6. Hauer, T.: Modellierung der Werkzeugabdrängung beim Reiben - Ableitung von Empfehlungen für die Gestaltung von Mehrschneidenreibahlen. Dissertation, TU Darmstadt (2012)

7. Geßner, F., Weigold, M., Abele, E.: Measuring and modelling of process forces during tapping using single tooth analogy process. Prod. Eng. Res. Dev. (2020). https://doi.org/10.1007/s11 740-020-01004-4

8. Özkaya, E.: FEM-basiertes Softwaresystem für die effiziente 3D-Gewindebohrsimulation und Werkzeugoptimierung mittels CFD-Simulation, 1. Auflage. Schriftenreihe des ISF, vol 89. Vulkan, Essen (2017)

9. Kim, G.M., Kim, B.H., Chu, C.N.: Estimation of cutter deflection and form error in ball-end milling processes. Int. J. Mach. Tools Manufact. 43, 917-924 (2003). https://doi.org/10.1016/ S0890-6955(03)00056-7

10. Smaoui, M., Bouaziz, Z., Zghal, A., et al.: Simulation of the deflected cutting tool trajectory in complex surface milling. Int. J. Adv. Manufact. Technol. 56, $463-474$ (2011). https://doi. org/10.1007/s00170-011-3213-X

11. Zeroudi, N., Fontaine, M.: Prediction of tool deflection and tool path compensation in ball-end milling. J. Intell. Manufact. 26, 425-445 (2013). https://doi.org/10.1007/s10845-013-0800-8

12. Moges, T.M., Desai, K.A., Rao, P.V.M.: Modeling of cutting force, tool deflection, and surface error in micro-milling operation. Int. J. Adv. Manufact. Technol. 98, 2865-2881 (2018). https://doi.org/10.1007/s00170-018-2415-x

13. Bölling, C.: Simulationsbasierte Auslegung mehrstufiger Werkzeugsysteme zur Bohrungsfeinbearbeitung am Beispiel der Ventilführungs- und Ventilsitzbearbeitung. Dissertation, TU Darmstadt (2018) 
14. Hasenfratz, C.: Modellgestützte Prozessauslegung zum linearen Schaftfräsen von tiefen Kavitäten in TiAl6V4 - Verdichterscheiben. Dissertation, TU Darmstadt (2018)

15. Dogra, A.P.S., DeVor, R.E., Kapoor, S.G.: Analysis of feed errors in tapping by contact stress model. J. Manufact. Sci. Eng. 124, 248-257 (2002). https://doi.org/10.1115/1.1454107

16. Mezentsev, O.A., DeVor, R.E., Kapoor, S.G.: Prediction of thread quality by detection and estimation of tapping faults. J. Manufact. Sci. Eng. 124, 643-650 (2002). https://doi.org/10. $1115 / 1.1475319$

17. Mezentsev, O.A., Zhu, R., DeVor, R.E., et al.: Use of radial forces for fault detection in tapping. Int. J. Mach. Tools Manufact. 42, 479-488 (2002). https://doi.org/10.1016/S08906955(01)00139-0

18. DIN Deutsches Institut für Normung e.V.: Gewinde - Begriffe und Bestimmungen für zylindrische Gewinde (DIN 2244:2002-05) (2002)

19. DIN Deutsches Institut für Normung e.V.: Maschinen-Gewindebohrer mit verstärktem Schaft für Metrisches ISO-Regelgewinde M1 bis M10 und Metrisches ISO-Feingewinde M1 × 0,2 bis M10 × 1,25 (DIN 371:2016-01) (2016)

20. Koenigsberger, F., Sabberwal, A.J.P.: An investigation into the cutting force pulsations during milling operations. Int. J. Mach. Tool Des. Res. 1, 15-33 (1961). https://doi.org/10.1016/00207357(61)90041-5

21. Kapoor, S.G., DeVor, R.E., Zhu, R., et al.: Development of mechanistic models for the prediction of machining performance: model building methodology. Mach. Sci. Technol. 2, 213-238 (1998). https://doi.org/10.1080/10940349808945669

Open Access This chapter is licensed under the terms of the Creative Commons Attribution 4.0 International License (http://creativecommons.org/licenses/by/4.0/), which permits use, sharing, adaptation, distribution and reproduction in any medium or format, as long as you give appropriate credit to the original author(s) and the source, provide a link to the Creative Commons license and indicate if changes were made.

The images or other third party material in this chapter are included in the chapter's Creative Commons license, unless indicated otherwise in a credit line to the material. If material is not included in the chapter's Creative Commons license and your intended use is not permitted by statutory regulation or exceeds the permitted use, you will need to obtain permission directly from the copyright holder.

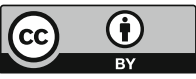

